\title{
The Effect of Growth Temperature of Seed Layer on the Structural and Optical Properties of ZnO Nanorods
}

\author{
Khyati Gautam $^{1 *}$, Inderpreet Singh ${ }^{2}$, P.K. Bhatnagar ${ }^{1}$, Koteswara Rao Peta ${ }^{1}$ \\ ${ }^{1}$ Department of Electronic Science, University of Delhi South Campus, Benito Juarej Road, \\ New Delhi-110021, India \\ ${ }^{2}$ Department of Electronics, SGTB Khalsa College, University of Delhi, Delhi-110007, India \\ *Corresponding author: Tel: +91-11-24110440, Fax: +91-11-24110440. \\ Email address: khyati34@gmail.com (Khyati Gautam).
}




\begin{abstract}
The structural and optical properties of $\mathrm{ZnO}$ nanorods are investigated as a function of growth temperature of the seed layer. The seed layer comprising of $\mathrm{ZnO}$ nanocrystallites is grown on ITO substrates at five different temperatures $\left(150-550{ }^{\circ} \mathrm{C}\right)$ and the nanorods are grown on the seed layer by the facile hydrothermal method. The seed layer grown at $350{ }^{\circ} \mathrm{C}$ is observed to be uniformly textured with c-axis orientation leading to the synthesis of vertically aligned nanorods with smaller diameter. The HR-TEM analysis and the intense peak along (002) direction in the XRD spectra of this sample implied that the nanorods possess c-axis orientation. An enhanced UV emission is also observed in the photoluminescence spectra of this sample. The diversity in the morphology and orientation of the seeds at different temperatures has been explained by the growth kinetics of the $\mathrm{ZnO}$ nanocrystallites.
\end{abstract}

KEYWORDS: ZnO nanorods, hydrothermal method, seed layer 


\section{Introduction}

Zinc oxide with its unique combination of wide bandgap (3.37 eV) and high exciton binding energy (60 meV) has drawn considerable attention of the researchers over the years. It possesses a family of nanostructures such as nanorods, nanotubes, nanoflowers, nanohelix etc. among which, $\mathrm{ZnO}$ nanorods are of particular interest because of their quasi 1-D structure, enhanced charge injection efficiency and improved emission that provides tremendous opportunity for their application in optoelectronic devices [1-6]. The performance of these devices depends majorly on the distribution and alignment of the nanorods over the substrate. If the distribution is homogeneous, then the optical and electrical contribution of the nanorods will be uniform throughout the device structure. Also, if the alignment of the nanorods is vertical, it enhances the charge injection across the device.

$\mathrm{ZnO}$ nanorods grown by gas-phase synthesis technique (chemical vapor deposition (CVD) [7], metal organic chemical vapor deposition (MOCVD) [8] vapor-liquid-solid (VLS) [9] and pulsed laser deposition (PLD) [10] are reported to be perfectly aligned, homogeneously distributed with high crystallinity. But these methods require high processing temperature and also their development cost is very high. On the other side, liquid phase synthesis (involving the hydrothermal method and electrochemical method) is simple and requires low temperature and therefore has become popular among the researchers for large scale production [4, 11-13]. However, the main challenge for researchers in the liquid phase synthesis is to reduce the defects, which are inherently introduced in the structure due to the growth technique. Many research groups are working towards obtaining good quality nanorods using hydrothermal method with minimal defects by controlling the growth parameters such as temperature, precursor concentration, $\mathrm{pH}$ value, growth time and the nature of the substrate. 
Recently, it has been observed that by depositing a seed layer comprising of $\mathrm{ZnO}$ nanocrystals over the substrate, the nanorods parameters, namely their alignment, diameter, density, crystallinity and photoluminescence (PL) can be precisely controlled [14-18]. It has been shown by Song et. al. [14] that the morphology of the $\mathrm{ZnO}$ nanorods is strongly dominated by the thickness and the crystal size of the seed layer. Ghayour et. al. [15] have described the effect of seed layer thickness on the alignment and diameter of the nanorods. They revealed that the alignment of nanorods depends on the crystallinity, grain size and RMS roughness of the seed layer. Wu et. al. [16] have proposed a molecule adsorption stabilization mechanism to explain the seed orientation. They concluded that the verticality of the nanorods array depends heavily on the seed orientation. It has been shown by Guillemin et. al. [17] that the growth of $\mathrm{ZnO}$ nanowires is limited by the mass transport of chemical precursors in solution, leading to the inverse relationship of their average diameter and length with their density. They concluded that the vertical alignment of $\mathrm{ZnO}$ nanowires and their density increases, when the seed layer texture is strengthened along the c-axis. In their recent publication [18] they have suggested an alternative approach for the formation of $\mathrm{ZnO}$ nanowire arrays with high structural and optical quality. It is based on the spontaneous transformation of a $\mathrm{ZnO}$ thin film into $\mathrm{ZnO}$ nanowires through simple annealing. The precursor concentration of the solution of $\mathrm{ZnO}$ seed layer is also found to affect the residual stress in the nanorods grown on these seeds.

In the present work, $\mathrm{ZnO}$ nanorods have been synthesized on $\mathrm{ZnO}$ seed layers that are grown at different temperatures, i.e. $150{ }^{\circ} \mathrm{C}$ to $550{ }^{\circ} \mathrm{C}$. The effect of different growth temperatures of seed layer on the morphological and optical properties of the as-grown $\mathrm{ZnO}$ nanorods has been investigated. The seed layer was synthesized by thermal decomposition of zinc acetate dihydrate in ethanol and the nanorods were grown over the seed layer by the facile hydrothermal method. 
The structural and optical properties of the nanorods were found to be strongly affected by the growth temperature of the seed layer.

\section{Material and methods}

The chemicals used for synthesizing $\mathrm{ZnO}$ seeds and nanorods viz. zinc acetate dihydrate, zinc nitrate hexahydrate and hexamethylenetetramine were commercially procured from Fisher Scientific. These constituents along with organic solvents and DI water were used to synthesize $\mathrm{ZnO}$ seed layer and nanorods as mentioned below.

\subsection{Synthesis of $\mathrm{ZnO}$ seed layer}

For $\mathrm{ZnO}$ seed layer, a solution of $0.005 \mathrm{M}$ zinc acetate dihydrate was prepared in ethanol. The solution was then kept in an ultrasonicator for $\sim 1$ hour for homogenization. Subsequently, an ITO coated glass substrate was taken and the so obtained solution was drop cast over it. It was then allowed to dry in the air and the process was repeated three times to ensure proper coating of the solution throughout the substrate. Five different substrates were obtained in this manner and were heated to five different temperatures, i.e. $150{ }^{\circ} \mathrm{C}, 250{ }^{\circ} \mathrm{C}, 350{ }^{\circ} \mathrm{C}, 450{ }^{\circ} \mathrm{C}$ and $550{ }^{\circ} \mathrm{C}$ (Sample A-E) in a muffle furnace for 20 minutes to prepare $\mathrm{ZnO}$ seed layer. These substrates coated with a seed layer of $\mathrm{ZnO}$ nanocrystals were further used to grow $\mathrm{ZnOnanorods}$ over them.

\subsection{Synthesis of $\mathrm{ZnO}$ nanorods}

For this purpose, an equimolar solution of $0.025 \mathrm{M}$ of Zinc nitrate hexahydrate and hexamethylenetetramine in DI water was taken. This solution was homogenized by ultrasonication for $\sim 1$ hour. After this, the solution was transferred to a petri dish and the ITO substrate already coated with the seed layer was immersed into the solution. The solution was 
then kept in an oven for 5 hours at $90{ }^{\circ} \mathrm{C}$. Subsequently, the substrate was taken out of the solution and then washed in DI water. Afterwards, the sample was again annealed to $100{ }^{\circ} \mathrm{C}$ for $10 \mathrm{~min}$. to completely remove the moisture. The same process was repeated for all the five samples.

The structural properties of the seeds and nanorods were studied using Scanning Electron Microscope (SEM) (JEOL JSM 6610LV), X-ray diffraction (XRD) (Bruker D8 X-ray Diffractometer with $\mathrm{CuK} \alpha$ source $(\lambda \sim 1.5406 \AA))$ and High Resolution Transmission Electron Microscope (HR-TEM) (FeiTecnai G2 STWIN HRTEM 200 kV). For optical characterization, the PL spectra of the samples were studied using Shimadzu spectrofluorophotometer model RF$5301 \mathrm{PC}$.

\section{Results and Discussion}

The SEM images of the nanorods grown on different seed layers are shown in fig. 1 (a). It is found that the ZnOnanorods grown on the sample $\mathrm{A}, \mathrm{D}$ and $\mathrm{E}$ are randomly aligned while the nanorods in samples B and C showed selective growth behavior. The nanorods in both these samples are found to be vertically aligned with narrow diameters. Between the two, the nanorods in sample $\mathrm{C}$ are found to exhibit improved alignment and high density over the substrate.

To verify the orientation of the as-grown nanorods, XRD measurements were done (fig. 2). The presence of significant peaks along (100), (002) and (101) directions in the XRD spectrum of sample A indicates the polycrystalline nature of these nanorods. It also confirms the random growth of nanorods for this sample. As expected, for samples B and C, intense peaks are observed along (002) direction, which is an indication of the improved crystallinity. This ensures the preferential growth of $\mathrm{ZnO}$ nanorods for both the cases. For sample $\mathrm{C}$, the diffraction peak 
pertaining to c-axis ((002) plane) is found to be more intense as compared with that of sample B. Sample C, therefore, showed highly crystalline nanorods with almost perfect vertical alignment. To further confirm the orientation, sample $\mathrm{C}$ was characterized by high resolution transmission electron microscopy (HR-TEM) (fig. 3). The spacing between the two adjacent lattice planes is found to be $0.26 \mathrm{~nm}$, which is consistent with the d-spacing (interplanar distance) of (002) plane of $\mathrm{ZnO}$ nanorods. For samples $\mathrm{D}$ and $\mathrm{E}$, as anticipated, the crystallinity is again found to be reduced with non-vertical growth over the substrate.

The PL spectra of all the samples (A-E) are shown in fig. 4. It is observed that the major luminescence of the nanorods is in the visible range, i.e. from 400 to $525 \mathrm{~nm}$. This emission is basically governed by the defect states present in the nanorod structure as explained by several researchers [19-22]. In addition to this, an emission is also observed in the UV region at $390 \mathrm{~nm}$, which is the basic signature of the near band edge recombination in $\mathrm{ZnO}$ structure. For sample $\mathrm{C}$, the ratio of intensity of near band edge emission to defect emission ( $\left.\mathrm{I}_{\underline{u v}} / \underline{\mathrm{I}}_{\mathrm{vi}}\right)$ is found to be maximum among all the samples (Table 1). This is the most significant indicator of superior crystal quality of this sample with lesser defects as compared to other samples [22-25]. It may also be mentioned that the UV emission from the nanorods is anisotropic in nature and is maximum along the c-axis [26]. This explains the enhanced UV emission in sample C, where nanorods are vertically aligned. 
Table 1: Ratio of maximum intensity of UV $(\sim 390 \mathrm{~nm})$ and visible emission $(\sim 438 \mathrm{~nm})$ of the nanorods (Sample A-E)

\begin{tabular}{ccc}
\hline Sample & $\begin{array}{r}\text { Seed growth temperature } \\
\left({ }^{\circ} \mathbf{C}\right)\end{array}$ & $\mathbf{I}_{\mathbf{u v}} / \mathbf{I}_{\mathbf{v i s}}$ \\
\hline A & 150 & 0.246 \\
B & 250 & 0.624 \\
C & 350 & 0.716 \\
D & 450 & 0.445 \\
E & 550 & 0.262 \\
\hline
\end{tabular}

Our results show that the $\mathrm{ZnO}$ nanorods grown over sample $\mathrm{C}$ are perfectly aligned with high crystallinity and enhanced UV emission. The growth temperature of seed layer thus, has a considerable impact on the morphology and crystallinity of the nanorods. As $\mathrm{ZnO}$ nanorods are well known to inherit the structural properties of the seed layer, therefore, SEM and XRD measurements were performed on the seed layer as well. Fig. 1 (b) gives the SEM images of the seed layers grown at different temperatures, i.e. $150-550{ }^{\circ} \mathrm{C}$ (sample A-E). The surface morphology of the seed layers in samples A, D and E are found to be poor. This can be considered as the root cause of the random alignment of $\mathrm{ZnO}$ nanorods for these samples. Another possible reason for the non-vertical growth of nanorods on these seed layers is depicted by the XRD spectra (fig 5). Three prominent peaks pertaining to (100), (002) and (101) planes 
are observed for all the seed layers. In order to verify the preferential orientation of seeds along c-axis, the texturing coefficient $\mathrm{C}_{\mathrm{hkl}}$ along the (002) peak is calculated using the following equation as suggested by Guillemin et. al. [27].

$C_{h k l}=\frac{\frac{I_{h k l}}{I_{0(h k l)}}}{\frac{1}{N} \sum_{1}^{N} \frac{I_{h k l}}{I_{0(h k l)}}}$

where $N$ is the number of peaks, $I_{\underline{h l} l}$ is the experimental peak intensity and $I_{0 h k l}$ is the peak intensity given by the JCPDS file 01-070-2551. Table 2 shows the value of texture coefficients $\underline{\text { for all the five seed samples. }}$

Table 2: Texturing coefficients $\mathrm{C}_{\mathrm{hkl}}$ along (002) direction for the seed layers in different samples.

Seed Sample

A

B

C

D

$\mathbf{E}$
Texturing coefficient $\left(\mathrm{C}_{002}\right)$

1.72

2.31

2.93

1.91

1.56

The texturing coefficient along the (002) direction is found to be higher in samples B and C with a maximum value of 2.93 in sample $C$. This shows that the seed layer for sample $\mathrm{C}$ is highly crystalline and has the maximum tendency to promote vertical and highly crystalline growth of 
$\underline{\mathrm{ZnO} \text { nanorods while other samples specially } \mathrm{A}, \mathrm{D} \text { and } \mathrm{E} \text { lack this possibility as indicated by their }}$ low texturing coefficient value. As expected, a uniform texture of $\mathrm{ZnO}$ nanocrystallites is also observed in the seed layer of samples B and C.

This observed diversity in the crystallinity and morphology of all the samples can be well understood by studying the growth kinetics of the nanocrystals in the seed layer. When the solution of zinc acetate dehydrate, is heated in a muffle furnace, the following set of reaction takes place as explained by several authors [28-30].

$$
\begin{aligned}
\mathrm{Zn}\left(\mathrm{CH}_{3} \mathrm{COO}\right)_{2} \cdot 2 \mathrm{H}_{2} \mathrm{O} & \rightarrow \mathrm{Zn}\left(\mathrm{CH}_{3} \mathrm{COO}\right)_{2}+2 \mathrm{H}_{2} \mathrm{O} \\
\mathrm{Zn}\left(\mathrm{CH}_{3} \mathrm{COO}\right)_{2} & \rightarrow \mathrm{Zn}^{2+}+2 \mathrm{CH}_{3} \mathrm{COO}^{-} \\
\mathrm{CH}_{3} \mathrm{COO}^{-}+\mathrm{CH}_{3} \mathrm{CH}_{2} \mathrm{OH} & \rightarrow \mathrm{CH}_{3} \mathrm{COOCH}_{2} \mathrm{CH}_{3}+\mathrm{OH}^{-} \\
\mathrm{Zn}^{2+}+2 \mathrm{OH}^{-} & \rightarrow \mathrm{ZnO}+\mathrm{H}_{2} \mathrm{O}
\end{aligned}
$$

In the beginning of seed layer formation (i.e. during the annealing phase), the thermal dehydration of zinc acetate dihydrate takes place [31-33], resulting in the formation of anhydrous zinc acetate (equation (1)) which further decomposes to give $\mathrm{Zn}^{2+}$ and acetate ions (equation (2)). Between the two $\mathrm{Zn}^{2+}$ ions quickly settles down on the ITO substrate and act as nucleation sites for the growth of seed layer. Being chemically active $\mathrm{Zn}^{2+}$ ions attract oppositely charged $\mathrm{OH}^{-}$ ions (produced by the reaction of ethanol with acetate ions (equation (3))) towards them, which further generates $\mathrm{O}^{2-}$ ions that binds itself with $\mathrm{Zn}^{2+}$. The $\mathrm{O}^{2-}$ ions again being highly negative, attracts $\mathrm{Zn}^{2+}$ and the process continues to form a stable $\mathrm{ZnO}$ structure. Among the various crystallographic planes of $\mathrm{ZnO}$, (002) plane is highly unstable and possess maximum surface energy because of its polar nature $[34,35]$. To attain an overall stable structure, molecular 
adsorption takes place at this plane thereby reducing the surface energy [16, 36]. This stabilization mechanism has been reported to be responsible for the orientation of $\mathrm{ZnO}$ seed layer [16].

In view of the fact that surface morphology and orientation is an intrinsic thermodynamic feature of crystal growth, our results suggest that there is a critical value of energy associated for efficient molecular adsorption for surface stabilization. At lower temperature $\left(150{ }^{\circ} \mathrm{C}\right)$, the thermal energy present in the system is insufficient, which does not effectively support the adsorption of molecules on (002) plane. On the other hand, at higher temperatures, i.e. $450{ }^{\circ} \mathrm{C}$ (sample D) and $550{ }^{\circ} \mathrm{C}$ (Sample E), a large amount of thermal energy is available, which enhances the kinetic energy of the system. As a result of this, the contributing ions namely $\mathrm{Zn}^{2+}$ and $\mathrm{O}^{2-}$ occupy random adsorption sites available at different crystallographic planes (as is evident from XRD spectra (fig. 4)). At intermediate growth temperatures, i.e. $250{ }^{\circ} \mathrm{C}$ and $350{ }^{\circ} \mathrm{C}$, the energy present in the system is optimum for adsorbates to interact and assemble on the crystal nuclei in an ordered manner, therefore, minimizing the surface energy of (002) plane. This results in the formation of a thin film of $\mathrm{ZnO}$ nanocrystals that evolves along the c-axis, making it the preferred orientation for the growth of the $\mathrm{ZnO}$ nanorods grown over them.

\section{Conclusion}

It can be concluded that different morphology and orientation of the $\mathrm{ZnO}$ seed layer were obtained at different growth temperatures, which subsequently affect the structural parameters and optical properties of the nanorods grown over them. The seed layer grown at a temperature of $350{ }^{\circ} \mathrm{C}$ (sample $\mathrm{C}$ ) exhibited best surface morphology and c-axis orientation. This, in turn, promotes the vertical growth of $\mathrm{ZnO}$ nanorods with high crystallinity and smaller diameters. The 
ratio of band edge emission to defect emission is also found to be maximum for this sample. The analysis of the growth kinetics of $\mathrm{ZnO}$ seed layer implied that the structural properties of $\mathrm{ZnO}$ seed layer were thermodynamically controlled at different temperatures.

\section{Acknowledgement}

This work is supported by the University of Delhi under the grant Research and Development (2013-2016) and DST India. Two of the authors, Khyati Gautam and P. K. Bhatnagar wishes to thank the University Grant Commission (UGC) India for supporting the research fellowship and BSR fellowship respectively.

\section{References}

[1] Q.-M. Fu, W. Cao, G.-W. Li, Z.-D. Lin, Z. Chen, C.-B. Xu, Y.-F. Tu, Z.-B. Ma, Blue/green electroluminescence from a $\mathrm{ZnO}$ nanorods/p-GaN heterojunction light emitting diode under different reverse bias, Applied Surface Science, 293 (2014) 225-228.

[2] Q. Yang, Y. Liu, C. Pan, J. Chen, X. Wen, Z.L. Wang, Largely Enhanced Efficiency in ZnO Nanowire/p-Polymer Hybridized Inorganic/Organic Ultraviolet Light-Emitting Diode by PiezoPhototronic Effect, Nano Letters, 13 (2013) 607-613.

[3] L. Schlur, A. Carton, P. Lévêque, D. Guillon, G. Pourroy, Optimization of a New ZnO Nanorods Hydrothermal Synthesis Method for Solid State Dye Sensitized Solar Cells Applications, The Journal of Physical Chemistry C, 117 (2013) 2993-3001.

[4] V. Strano, E. Smecca, V. Depauw, C. Trompoukis, A. Alberti, R. Reitano, I. Crupi, I. Gordon, S. Mirabella, Low-cost high-haze films based on $\mathrm{ZnO}$ nanorods for light scattering in thin c-Si solar cells, Applied Physics Letters, 106 (2015) 013901.

[5] S. Ranwa, P.K. Kulriya, V.K. Sahu, L.M. Kukreja, M. Kumar, Defect-free ZnO nanorods for low temperature hydrogen sensor applications, Applied Physics Letters, 105 (2014) 213103.

[6] L. Wang, Y. Kang, X. Liu, S. Zhang, W. Huang, S. Wang, ZnO nanorod gas sensor for ethanol detection, Sensors and Actuators B: Chemical, 162 (2012) 237-243.

[7] S.S. Shariffudin, N.Z. Abidin, N.Z. Yahya, A.A. Aziz, S.H. Herman, M. Rusop, Hybrid organic-inorganic light emitting diode using $\mathrm{ZnO}$ nanorods as electron transport layer, in: Micro and Nanoelectronics (RSM), 2013 IEEE Regional Symposium on, 2013, pp. 340-343.

[8] I. Ok Jung, J.Y. Park, S.S. Kim, Substrate dependent growth modes of ZnO nanorods grown by metalorganic chemical vapor deposition, Journal of Crystal Growth, 355 (2012) 78-83.

[9] N.H. Alvi, W.u. Hassan, B. Farooq, O. Nur, M. Willander, Influence of different growth environments on the luminescence properties of $\mathrm{ZnO}$ nanorods grown by the vapor-liquid-solid (VLS) method, Materials Letters, 106 (2013) 158-163. 
[10] Q. Li, K. Gao, Z. Hu, W. Yu, N. Xu, J. Sun, J. Wu, Photoluminescence and Lasing Properties of Catalyst-Free ZnO Nanorod Arrays Fabricated by Pulsed Laser Deposition, The Journal of Physical Chemistry C, 116 (2012) 2330-2335.

[11] S.-L. Zhao, P.-Z. Kan, Z. Xu, C. Kong, D.-W. Wang, Y. Yan, Y.-S. Wang, Electroluminescence of $\mathrm{ZnO}$ nanorods/MEH-PPV heterostructure devices, Organic Electronics, 11 (2010) 789-793.

[12] R.B. Gupta, J. Kumar, D. Madhwal, I. Singh, I. Kaur, L.M. Bhardwaj, S. Nagpal, P.K. Bhatnagar, P.C. Mathur, Improvement in the luminous efficiency of MEH-PPV based light emitting diodes using zinc oxide nanorods grown by the electrochemical deposition technique on ITO substrates, Physica Scripta, 84 (2011) 015705.

[13] L. Vayssieres, Growth of Arrayed Nanorods and Nanowires of $\mathrm{ZnO}$ from Aqueous Solutions, Advanced Materials, 15 (2003) 464-466.

[14] J. Song, S. Lim, Effect of Seed Layer on the Growth of ZnO Nanorods, The Journal of Physical Chemistry C, 111 (2007) 596-600.

[15] H. Ghayour, H.R. Rezaie, S. Mirdamadi, A.A. Nourbakhsh, The effect of seed layer thickness on alignment and morphology of ZnO nanorods, Vacuum, 86 (2011) 101-105.

[16] W. Wu, G. Hu, S. Cui, Y. Zhou, H. Wu, Epitaxy of Vertical ZnO Nanorod Arrays on Highly (001)-Oriented ZnO Seed Monolayer by a Hydrothermal Route, Crystal Growth \& Design, 8 (2008) 4014-4020.

[17] S. Guillemin, V. Consonni, E. Appert, E. Puyoo, L. Rapenne, H. Roussel, Critical Nucleation Effects on the Structural Relationship Between ZnO Seed Layer and Nanowires, The Journal of Physical Chemistry C, 116 (2012) 25106-25111.

[18] S. Guillemin, E. Sarigiannidou, E. Appert, F. Donatini, G. Renou, G. Bremond, V. Consonni, Spontaneous shape transition of thin films into $\mathrm{ZnO}$ nanowires with high structural and optical quality, Nanoscale, 7 (2015) 16994-17003.

[19] A.B. Djurišić, Y.H. Leung, Optical Properties of ZnO Nanostructures, Small, 2 (2006) 944961.

[20] L. Li, S. Pan, X. Dou, Y. Zhu, X. Huang, Y. Yang, G. Li, L. Zhang, Direct Electrodeposition of $\mathrm{ZnO}$ Nanotube Arrays in Anodic Alumina Membranes, The Journal of Physical Chemistry C, 111 (2007) 7288-7291.

[21] L. Dai, X.L. Chen, W.J. Wang, T. Zhou, B.Q. Hu, Growth and luminescence characterization of large-scale zinc oxide nanowires, Journal of Physics: Condensed Matter, 15 (2003) 2221.

[22] E.G. Barbagiovanni, R. Reitano, G. Franzo, V. Strano, A. Terrasi, S. Mirabella, Radiative mechanism and surface modification of four visible deep level defect states in $\mathrm{ZnO}$ nanorods, Nanoscale, 8 (2016) 995-1006.

[23] J.J. Hassan, M.A. Mahdi, S.J. Kasim, N.M. Ahmed, H. Abu Hassan, Z. Hassan, High sensitivity and fast response and recovery times in a $\mathrm{ZnO}$ nanorod array/p-Si self-powered ultraviolet detector, Applied Physics Letters, 101 (2012) 261108.

[24] S.N.Q.A. Abd Aziz, S.-Y. Pung, Z. Lockman, Growth of Fe-doped ZnO nanorods using aerosol-assisted chemical vapour deposition via in situ doping, Applied Physics A, 116 (2014) 1801-1811.

[25] H. Zeng, Y. Cao, S. Xie, J. Yang, Z. Tang, X. Wang, L. Sun, Synthesis, optical and electrochemical properties of $\mathrm{ZnO}$ nanowires/graphene oxide heterostructures, Nanoscale Research Letters, 8 (2013) 1-6. 
[26] N.E. Hsu, W.K. Hung, Y.F. Chen, Origin of defect emission identified by polarized luminescence from aligned $\mathrm{ZnO}$ nanorods, Journal of Applied Physics, 96 (2004) 4671-4673.

[27] S. Guillemin, E. Appert, H. Roussel, B. Doisneau, R. Parize, T. Boudou, G. Bremond, V. Consonni, Controlling the Structural Properties of Single Step, Dip Coated ZnO Seed Layers for Growing Perfectly Aligned Nanowire Arrays, The Journal of Physical Chemistry C, 119 (2015) 21694-21703.

[28] J.-S. Park, I. Mahmud, H.J. Shin, M.-K. Park, A. Ranjkesh, D.K. Lee, H.-R. Kim, Effect of surface energy and seed layer annealing temperature on $\mathrm{ZnO}$ seed layer formation and $\mathrm{ZnO}$ nanowire growth, Applied Surface Science, 362 (2016) 132-139.

[29] H. Du, F. Yuan, S. Huang, J. Li, Y. Zhu, A New Reaction to ZnO Nanoparticles, Chemistry Letters, 33 (2004) 770-771.

[30] Z. Hu, G. Oskam, R.L. Penn, N. Pesika, P.C. Searson, The Influence of Anion on the Coarsening Kinetics of ZnO Nanoparticles, The Journal of Physical Chemistry B, 107 (2003) 3124-3130.

[31] C.-C. Lin, Y.-Y. Li, Synthesis of $\mathrm{ZnO}$ nanowires by thermal decomposition of zinc acetate dihydrate, Materials Chemistry and Physics, 113 (2009) 334-337.

[32] L.E. Greene, M. Law, D.H. Tan, M. Montano, J. Goldberger, G. Somorjai, P. Yang, General Route to Vertical $\mathrm{ZnO}$ Nanowire Arrays Using Textured ZnO Seeds, Nano Letters, 5 (2005) 1231-1236.

[33] A. Vithal Ghule, B. Lo, S.-H. Tzing, K. Ghule, H. Chang, Y. Chien Ling, Simultaneous thermogravimetric analysis and in situ thermo-Raman spectroscopic investigation of thermal decomposition of zinc acetate dihydrate forming zinc oxide nanoparticles, Chemical Physics Letters, 381 (2003) 262-270.

[34] L. Vayssieres, K. Keis, A. Hagfeldt, S.-E. Lindquist, Three-Dimensional Array of Highly Oriented Crystalline ZnO Microtubes, Chemistry of Materials, 13 (2001) 4395-4398.

[35] Y.-K. Hsu, Y.-G. Lin, Y.-C. Chen, Polarity-dependent photoelectrochemical activity in ZnO nanostructures for solar water splitting, Electrochemistry Communications, 13 (2011) 13831386.

[36] Z. Guo, L. Tan, Fundamentals and applications of nanomaterials, Artech House, 2014. 


\section{Figures and Figure Captions}

Fig. 1

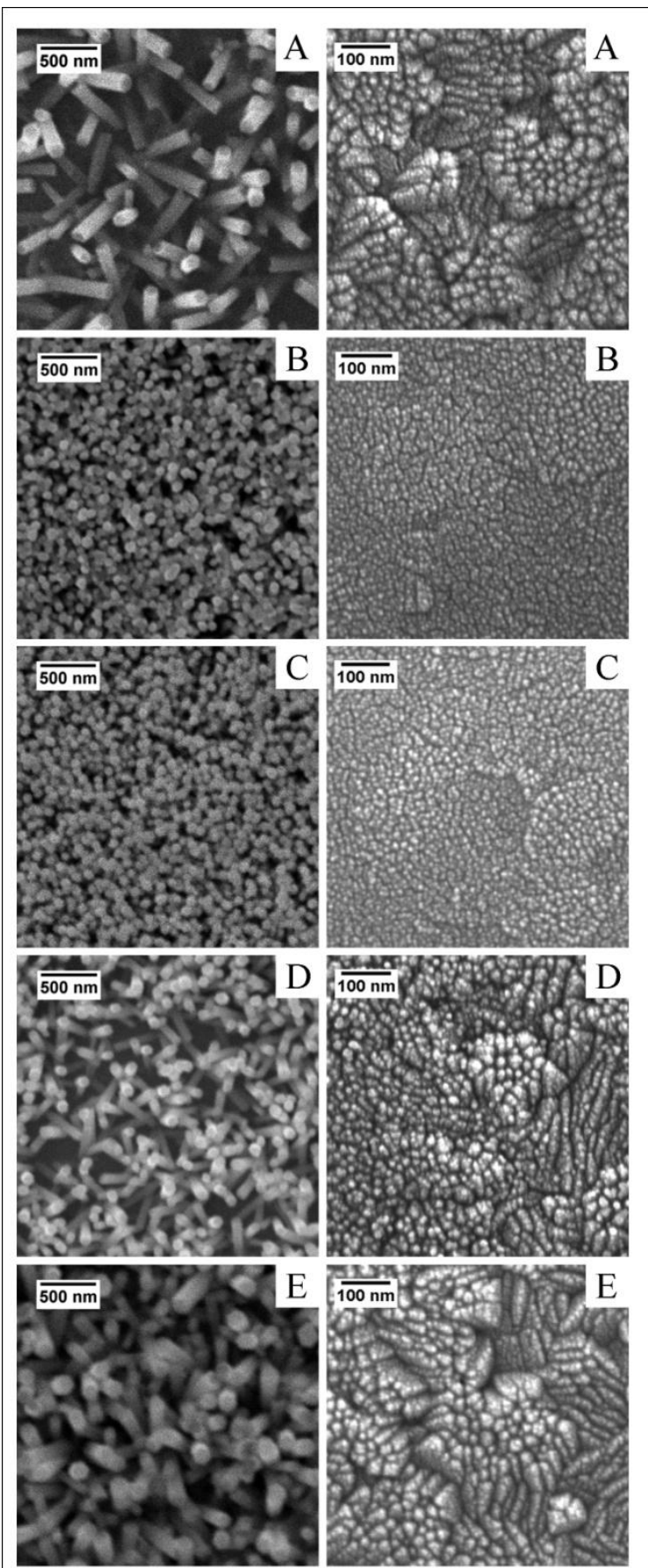

(a)

(b) 
Fig. 2

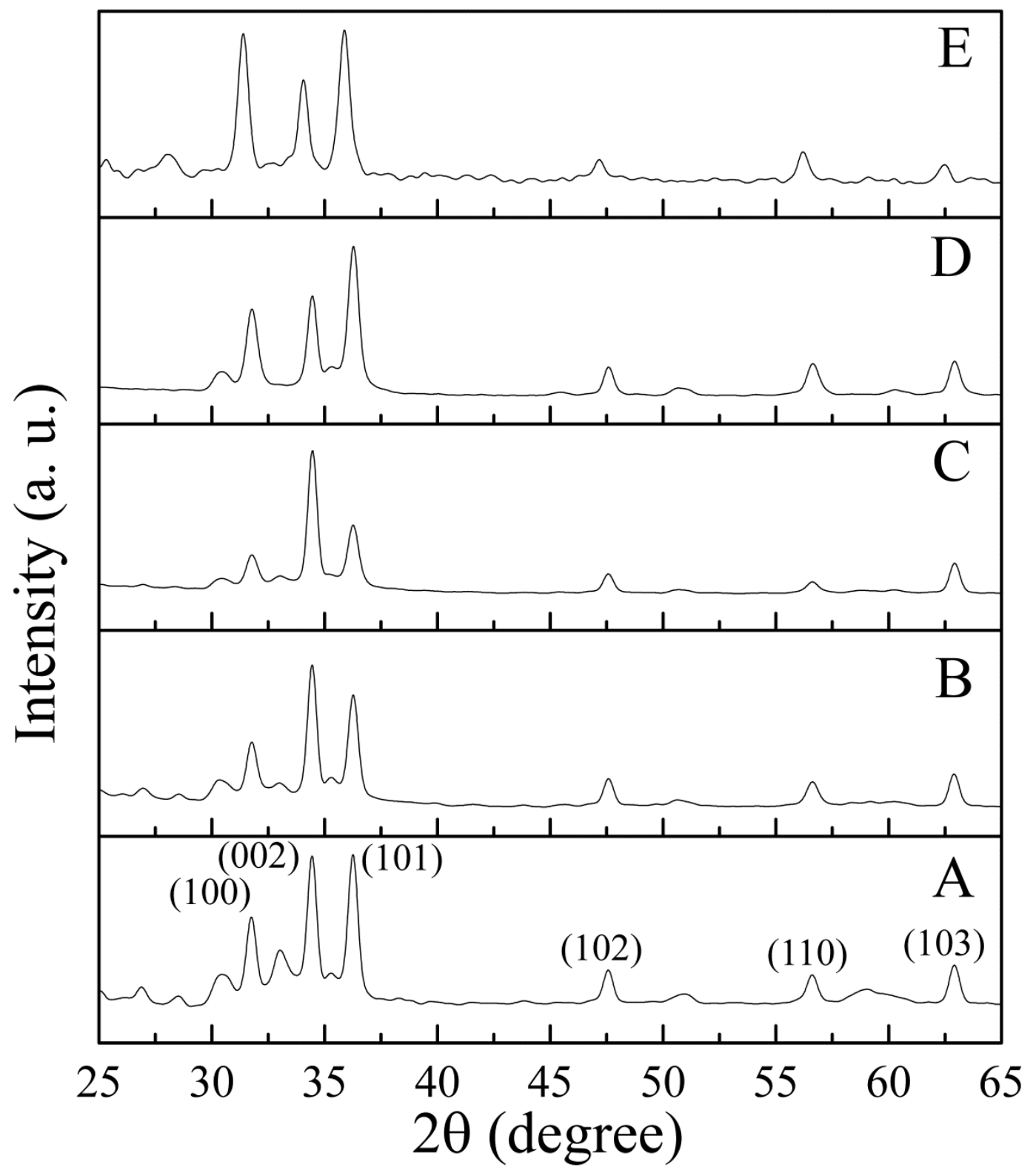


Fig. 3

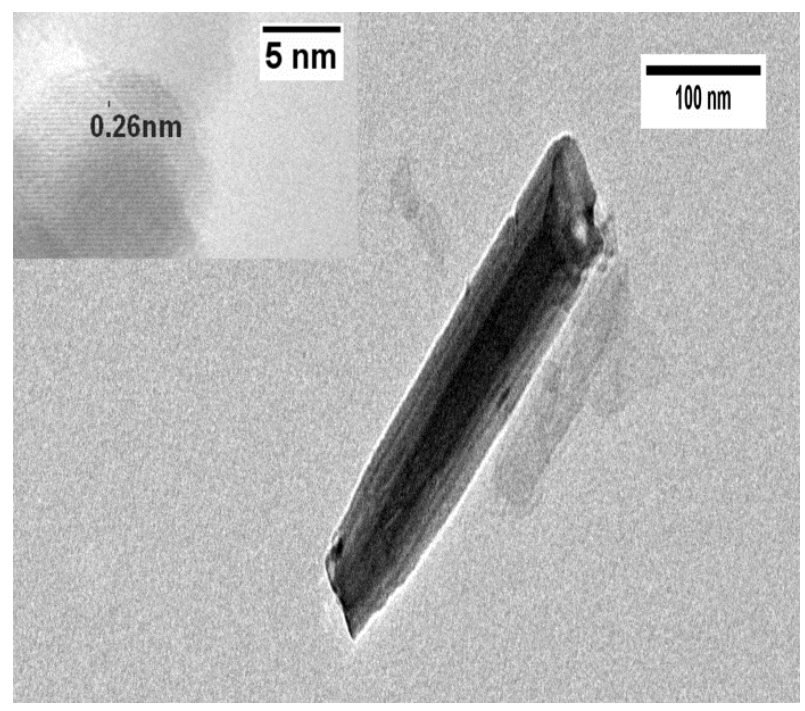


Fig. 4

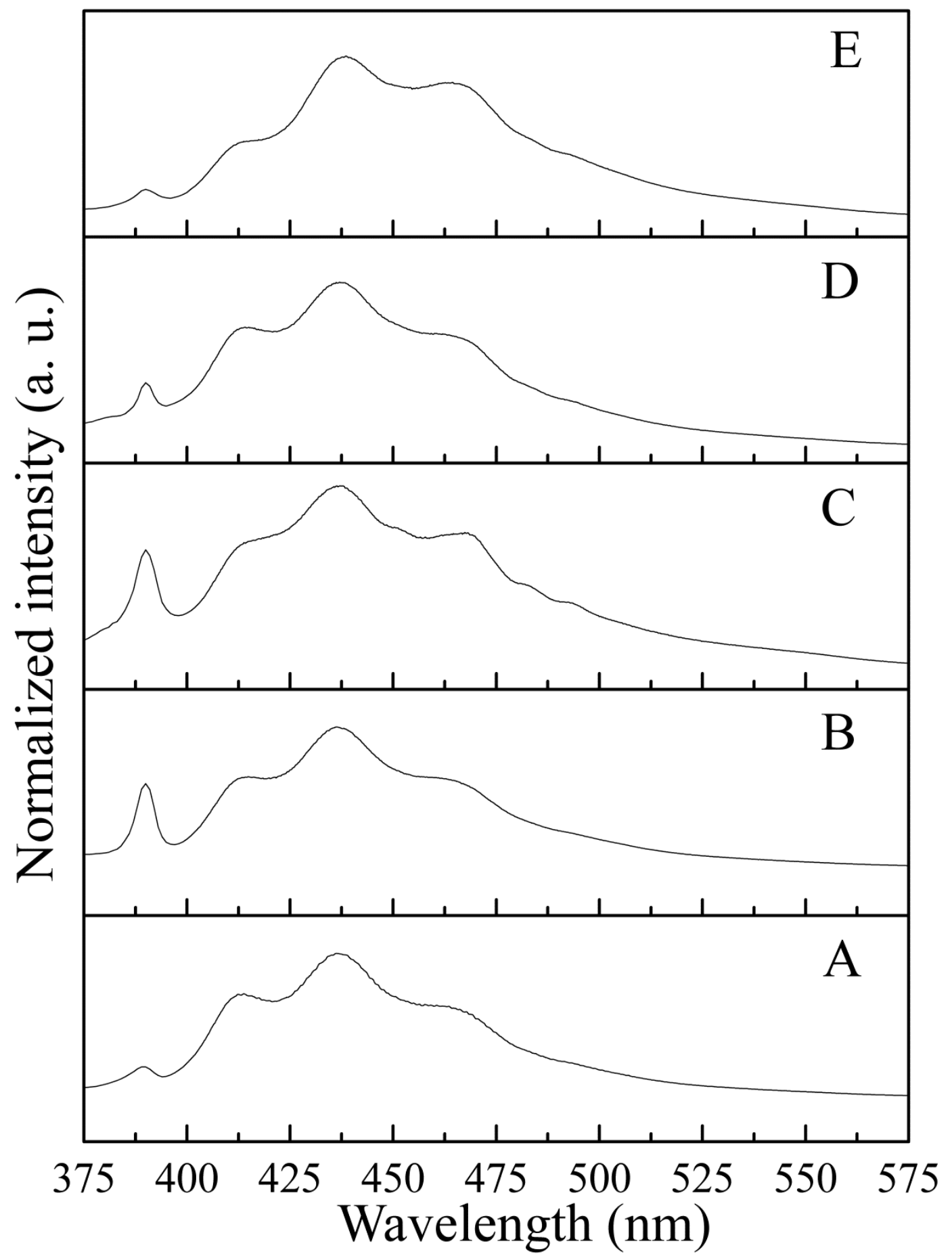


Fig. 5

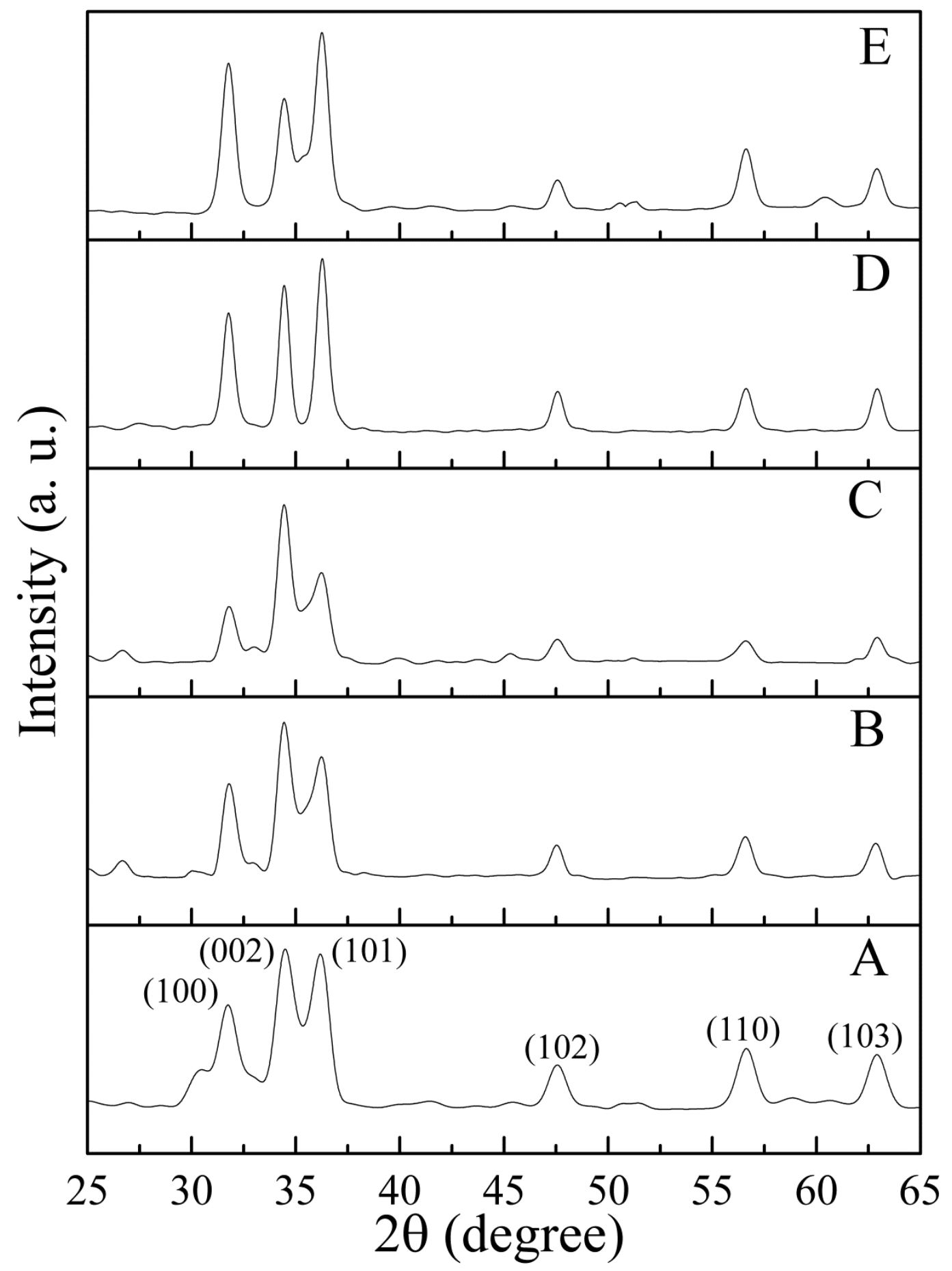




\section{Figure captions}

Fig.1: Typical SEM images of (a) $\mathrm{ZnO}$ nanorods and (b) the corresponding $\mathrm{ZnO}$ seed layers (Sample A- $150^{\circ} \mathrm{C}$, Sample B- $250^{\circ} \mathrm{C}$, Sample C- $350^{\circ} \mathrm{C}$, Sample D- $450^{\circ} \mathrm{C}$ and Sample E-550 ${ }^{\circ} \mathrm{C}$ ).

Fig.2: XRD spectra of ZnO nanorods (Sample A-E).

Fig.3: HR-TEM image of $\mathrm{ZnO}$ nanorod in sample $\mathrm{C}$.

Fig.4: Room temperature PL spectra of $\mathrm{ZnO}$ nanorods (Samples A-E)

Fig.5: XRD spectra of $\mathrm{ZnO}$ seed layers (sample A-E) 